\title{
Congenital Analbuminemia in a Korean Male Diagnosed with Single Nucleotide Polymorphism in the ALB Gene: The First Case Reported in Korea
}

\author{
Youngji Kim ${ }^{1}$, Ye Seul Yang ${ }^{2}$, Sung Sup Park ${ }^{3}$, Man Jin Kim ${ }^{3}$ Cheol Min Shin ${ }^{1}$, and Sung Hee Choi ${ }^{1}$ \\ ${ }^{1}$ Department of Internal Medicine, Seoul National University Bundang Hospital, Seongnam; \\ Departments of ${ }^{2}$ Internal Medicine and ${ }^{3}$ Laboratory Medicine, Seoul National University Hospital, Seoul, Korea.
}

Congenital analbuminemia (CAA) is an autosomal recessive disease characterized by extremely low serum levels of albumin. CAA is caused by various homozygous or heterozygous mutations of the $A L B$ gene. Patients often exhibit no clinical symptoms, aside from rare accompanying conditions, such as fatigue, ankle edema, and hypotension. This case report describes the case of a 28-year-old asymptomatic Korean male referred to our center with hypocalcemia, vitamin D deficiency, and hypoalbuminemia who was diagnosed with CAA. To determine the cause of hypoalbuminemia in the patient, laboratory tests, radiological examination, and DNA sequencing were performed. The patient was confirmed to not exhibit any other clinical conditions that can induce hypoalbuminemia and was diagnosed with CAA using DNA sequencing. The present case of CAA is the first to be reported in Korea.

Key Words: Hypoalbuminemia; hypocalcemia; vitamin D deficiency; sequence analysis, DNA

\section{INTRODUCTION}

Congenital analbuminemia (CAA) is an autosomal recessive disease characterized by extremely low levels of serum albumin without specific causes that can induce hypoalbuminemia (i.e., reduced protein synthesis due to hepatic dysfunction or re-distribution of protein aside from loss of protein from blood vessels in the kidneys or gastrointestinal tract). Since the absence of key serum proteins in adults can be partially offset by increased synthesis of other serum proteins, this condition is usually considered to be benign. Therefore, patients with CAA typically only exhibit very mild clinical symptoms, such as fatigue, ankle edema, and hypotension. $\cdot^{1-4}$

Received: April 29, 2019 Accepted: May 21, 2019

Corresponding author: Sung Hee Choi, MD, PhD, Department of Internal Medicine, Seoul National University Bundang Hospital, 82 Gumi-ro 173beon-gil, Bundanggu, Seongnam 13620, Korea.

Tel: 82-31-787-7003, Fax: 82-31-787-4050, E-mail: shchoimd@gmail.com

-The authors have no potential conflicts of interest to disclose.

(c) Copyright: Yonsei University College of Medicine 2019

This is an Open Access article distributed under the terms of the Creative Commons Attribution Non-Commercial License (https://creativecommons.org/licenses/ by-nc/4.0) which permits unrestricted non-commercial use, distribution, and reproduction in any medium, provided the original work is properly cited.
CAA diagnosis relies on the elimination of other clinical conditions that can lead to hypoalbuminemia and sequencing of the $A L B$ gene to detect mutations. In all reported cases, a mutation in $A L B$ located on chromosome 4 (4q11-13) has been identified as a driver of CAA and is induced by homozygous or heterozygous DNA deficiency. ${ }^{5}$

\section{CASE REPORT}

In January 2018, a 28-year-old Korean male visited Department of Endocrinology, Seoul National University Bundang Hospital because of hypoalbuminemia, hypoproteinemia, hypocalcemia, and vitamin $\mathrm{D}$ deficiency that had been detected during a health check-up. The patient had not been experiencing physical discomfort. There was no relevant personal or family medical history. Height and weight were $170 \mathrm{~cm}$ and $63 \mathrm{~kg}$. Physical examination revealed a blood pressure of 107/70 mm Hg, pulse rate of 70 per minute, respiration of 18 per minute, and body temperature of $36.8^{\circ} \mathrm{C}$. Cardiovascular, respiratory, abdominal, and neurological assessments produced normal outcomes.

Blood test outcomes indicated normal complete blood 
counts and electrolytes. In addition, liver function test and thyroid function test outcomes were normal. Blood abnormalities were hypoproteinemia, hypoalbuminemia, moderate hypocalcemia, vitamin D deficiency, and elevated parathyroid hormone (PTH) and alkaline phosphatase (ALP) levels.

We performed kidney function, complement, spot urine, and albuminuria tests to eliminate the possibility of nephrotic syndrome, and the outcomes were normal. All laboratory test outcomes are summarized in Table 1. A kidney ultrasound examination revealed kidneys of normal size with normal parenchyma. Esophagogastroduodenoscopy outcomes were normal, and the patient did not exhibit suspicious symptoms of protein loss (e.g., diarrhea). The patient showed elevated PTH levels and underwent a parathyroid scan, which proved normal. Dual energy X-ray absorptiometry confirmed a normal level of bone density: Z-scores were -1.0 [bone mineral density (BMD) $0.703 \mathrm{~g} / \mathrm{cm}^{2}$ ] on the left femoral and -0.8 (BMD 0.858 $\mathrm{g} / \mathrm{cm}^{2}$ ) on the spine (Fig. 1).

Serum protein electrophoresis was performed to detect low albumin concentrations and compensatory increases of nonalbumin proteins, especially $\alpha 1$ and $\alpha 2$ globulin fractions (Table 1). To confirm the diagnosis of CAA at the molecular level, we performed $A L B$ mutation analysis. DNA sequencing revealed a novel mutation of heterozygous single nucleotide polymorphism (SNP) causing $\mathrm{C}>\mathrm{T}$ transition at position c.1668 $\mathrm{C}>\mathrm{T}$, p.Leu556= in the $A L B$ gene (Fig. 2).

Daily oral consumption of calcium $500 \mathrm{mg}$ and vitamin D 1000 IU was commenced to treat hypocalcemia and vitamin D deficiency. At an outpatient follow-up visit after 3 months, the physical examination outcomes were still normal. Blood 25(OH)D levels had increased from 2.4 to $19.3 \mathrm{ng} / \mathrm{mL}$. PTH levels had decreased from 234 to $141 \mathrm{pg} / \mathrm{mL}$, and ALP levels had decreased from 116 to $104 \mathrm{IU} / \mathrm{L}$. Throughout five outpatient follow-up visits, serum albumin concentrations remained below $2.2 \mathrm{~g} / \mathrm{dL}$, and no specific clinical symptoms or signs were evident.

This study was approved for exemption of subject consent by Seoul National University Bundang Hospital Institutional Review Board (IRB No. B-1905/538-701).

\section{DISCUSSION}

The diagnosis of CAA is typically based on hematological indices, serum protein electrophoresis, and genetic analysis. Serum albumin concentrations can vary from 1 to $10 \mathrm{~g} / \mathrm{dL} .{ }^{1} \mathrm{CAA}$ is extremely rare, with approximately 70 cases reported worldwide. The cases are constantly being updated in the albuminemia registry. ${ }^{5}$ Thus far, all molecular level studies on CAA have indicated that a mutation in the $A L B$ gene near the centromere of chromosome 4 (4q11-13, 74269972-74287129) is the driver of this disease. The $A L B$ gene is located on chromosome 4 and is divided into 15 exons by 14 introns. ${ }^{6}$ Identifica-
Table 1. Laboratory Findings

\begin{tabular}{|c|c|c|}
\hline Analyte & Results & Normal reference range \\
\hline Hemoglobin (g/dL) & 15.7 & $13-17$ \\
\hline White blood cells $(1000 / \mu \mathrm{L})$ & 3.6 & $4.0-10.0$ \\
\hline Platelets $(1000 / \mu \mathrm{L})$ & 142 & $130-400$ \\
\hline Blood urea nitrogen (mg/dL) & 10.0 & 10-26 \\
\hline Creatinine (mg/dL) & 0.69 & $0.7-1.4$ \\
\hline $\mathrm{Na} / \mathrm{K}(\mathrm{mmol} / \mathrm{L})$ & $143 / 4.4$ & $135-145 / 3.5-5.5$ \\
\hline Serum total protein (g/dL) & 3.6 & $6.0-8.0$ \\
\hline Serum albumin (g/dL) & 2.2 & $3.3-5.2$ \\
\hline a1 globulin (relative) (\%) & $2.4-4.4$ & 9.7 \\
\hline a2 globulin (relative) (\%) & $6.0-10.7$ & 20.4 \\
\hline$\beta 1$ globulin (relative) (\%) & $4.6-6.7$ & 6.4 \\
\hline$\beta 2$ globulin (relative) (\%) & $3.3-6.3$ & 5.0 \\
\hline$\gamma$ globulin (relative) (\%) & $12.6-22.2$ & 8.6 \\
\hline Total bilirubin (mg/dL) & 0.37 & $0.2-1.20$ \\
\hline AST (IU/L) & 38 & $0-40$ \\
\hline ALT (IU/L) & 15 & $0-40$ \\
\hline Total cholesterol (mg/dL) & 140 & $0-200$ \\
\hline LDL cholesterol (mg/dL) & 77 & 55-155 \\
\hline HDL cholesterol (mg/dL) & 37 & $35-55$ \\
\hline Triglycerides (mg/dL) & 62 & $0-150$ \\
\hline Calcium (mg/dL) & 6.5 & $8.8-10.5$ \\
\hline lonized calcium (mmol/L) & 1.015 & $1.05-1.35$ \\
\hline Phosphate (mg/dL) & 3.5 & $2.5-4.5$ \\
\hline ALP (IU/L) & 116 & $30-115$ \\
\hline 25(OH)D (ng/mL) & 2.4 & $>20$ \\
\hline $\operatorname{lgG}(\mathrm{mg} / \mathrm{dL})$ & 248 & 700-1700 \\
\hline $\lg A$ (mg/dL) & 54 & 90-400 \\
\hline $\operatorname{lgM}(\mathrm{mg} / \mathrm{dL})$ & 71.9 & $45-230$ \\
\hline Lactate dehydrogenase (IU/L) & 185 & $100-225$ \\
\hline C3 (mg/dL) & 85 & 70-150 \\
\hline C4 (mg/dL) & 28 & $10-35$ \\
\hline Urine ACR (mg/g) & $<1.46$ & $<30$ \\
\hline Urine microalbumin (mg/dL) & $<0.3$ & $<15$ \\
\hline Urine protein (mg/dL) & 74 & $1-114$ \\
\hline PTH (intact) (pg/mL) & 234 & 8-76 \\
\hline fT4 (ng/dL) & 1.05 & $0.93-1.70$ \\
\hline $\mathrm{TSH}(\mu \mathrm{IU} / \mathrm{mL})$ & 3.07 & $0.27-4.20$ \\
\hline
\end{tabular}

AST, aspartate aminotransferase; ALT, alanine aminotransferase; LDL, lowdensity lipoprotein; HDL, high-density lipoprotein; ALP, alkaline phosphatase; 25(OH)D, 25-hydroxy vitamin D; IgG, immunoglobulin G; IgA, immunoglobulin $\mathrm{A}$; IgM, immunoglobulin $\mathrm{M}$; C3, complement component 3; C4, complement component 4; urine $\mathrm{ACR}$, urine albumin to creatinine ratio; PTH (intact), intact parathyroid hormone; fT4, free thyroxine; TSH, thyroid stimulating hormone.

tion of various mutations causing the onset of CAA suggests that the disease is genetically heterogeneous. ${ }^{5,6}$

CAA is a risk factor of high morbidity and mortality during pregnancy and infancy, indicating that albumin plays a critical role in the prenatal and perinatal periods. ${ }^{7,8}$ However, since a low level of serum albumin can be partially supplemented by increased levels of other serum proteins, CAA in adults does 

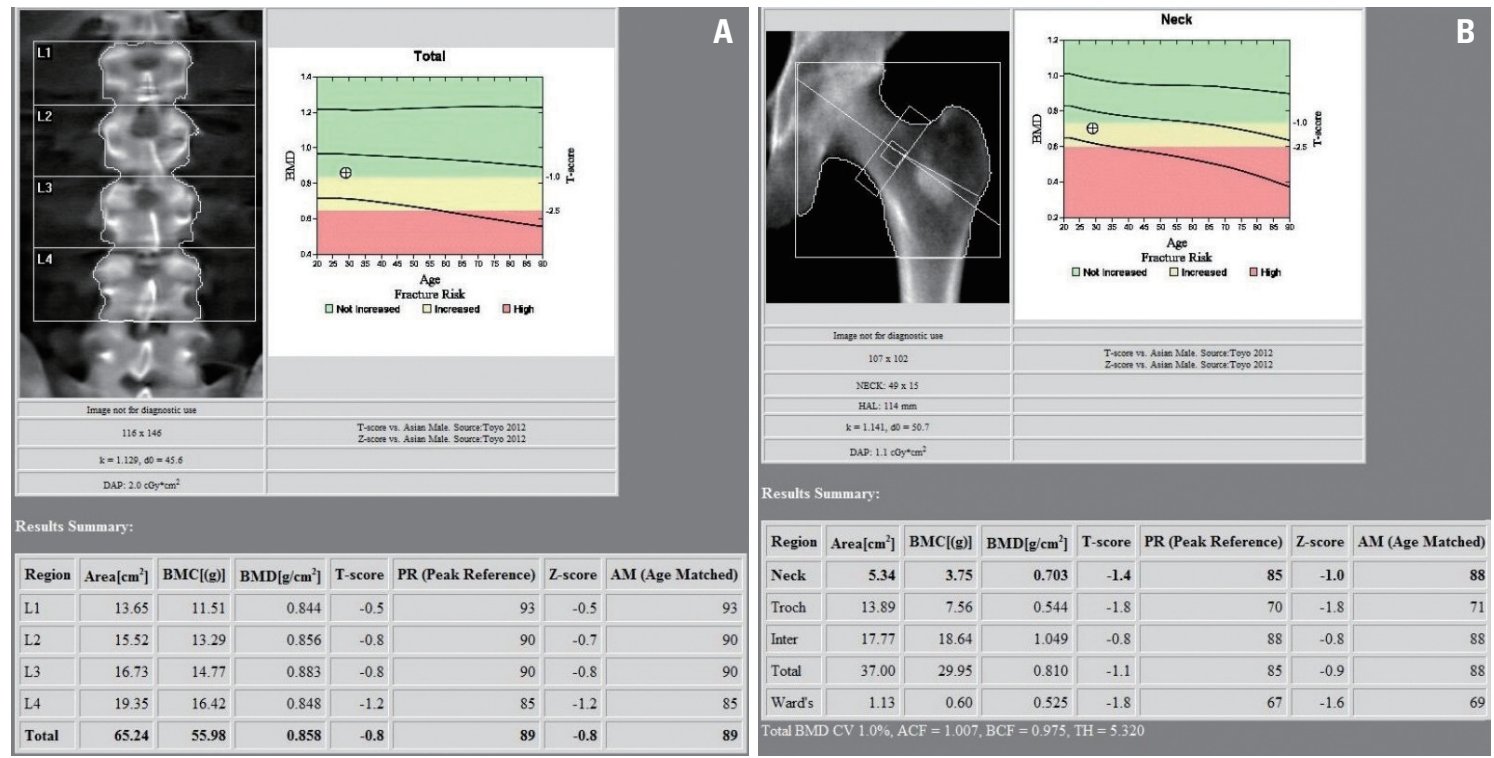

Fig. 1. Bone mineral density (BMD) in the patient with congenital analbuminemia at the lumbar spine $(A)$ and left femur (B). $L 1$, lumbar spine 1; $L 2$, lumbar spine 2; L3, Lumbar spine 3; L4, Lumbar spine 4; DAP, dose area product; HAL, hip axis length; BMC, bone mineral content; Troch, trochanter; Inter, intertrochanter; Ward's, Ward's triangle; CV, coefficient of variation; ACF, autocorrelation function; BCF, bias correction; TH, total hip.

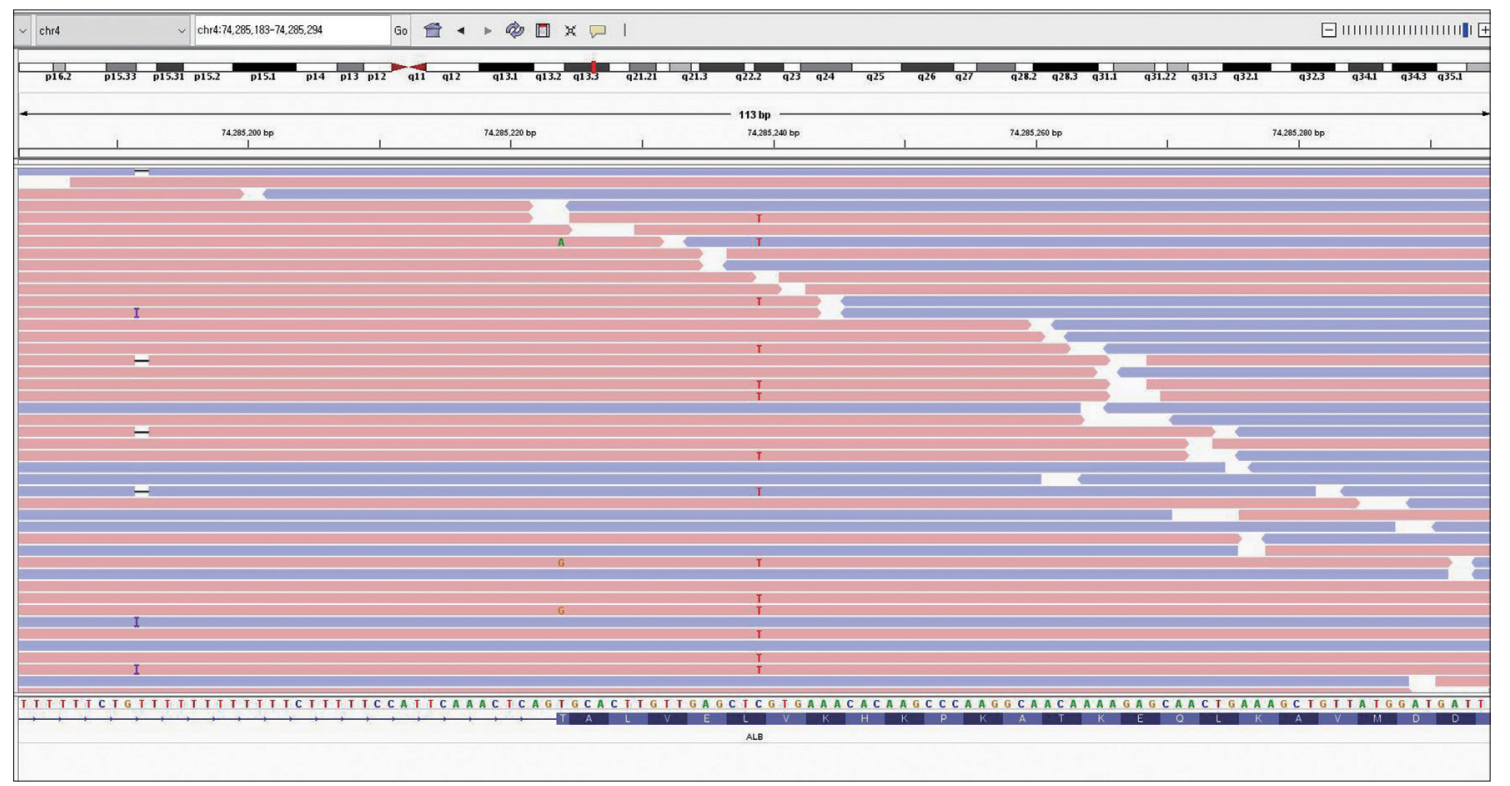

Fig. 2. ALB gene mutation analysis reveals NM_000477.5(ALB): c.1668C >T, p.Leu556=, heterozygote. chr4, chromosome 4; bp, base pair.

not result in clear symptoms and, thus, is considered a relatively benign disease. The benign features of CAA often lead to a misdiagnosis or delayed diagnosis of this rare condition. ${ }^{9}$

Serum albumin is a key transporter of serum calcium. Approximately $45 \%$ of circulating calcium is attached to serum albumin. ${ }^{2}$ It is expected that a patient with low serum albumin concentrations will exhibit low levels of total serum calcium despite having normal levels of biologically active ionized calcium. ${ }^{2}$ In addition, serum albumin acts as a transporter of vitamin D. The majority of 25(OH)D and 1,25-Dihydroxyvitamin $\mathrm{D}$ circulating in the bloodstream is tightly bound to the vitamin $\mathrm{D}$ binding protein, $10-15 \%$ is bound to albumin, and $<1 \%$ of circulating vitamin $\mathrm{D}$ exists in an unbound form..$^{10}$ Therefore, hypoalbuminemia may have effects on vitamin D deficiency. Nonetheless, hypocalcemia and vitamin D deficiency are thought to rarely affect the bone density of healthy young males (as in this case report), although they may have more severe effects in different age groups. ${ }^{7,8}$

The only limitation of this study was that the medical history of family members could only be assessed via question-answer interviews. We could not confirm the history of hypoalbuminemia in the patient's family members, and the presence of ge- 
netic mutations could not be assessed.

The 28-year-old Korean male patient harbored a heterozygous SNP c.1668C>T, p.Leu556= in the $A L B$ gene. The patient presented with hypoalbuminemia with accompanying hypocalcemia and vitamin D deficiency, but no other clinical symptoms. Continued interest in this rare disease and efforts in genetic diagnosis will contribute to uncovering the molecular genetic basis of CAA.

\section{AUTHOR CONTRIBUTIONS}

Conceptualization: Sung Hee Choi. Data curation: Youngji Kim. Formal analysis: Youngji Kim. Investigation: Sung Hee Choi. Methodology: Sung Hee Choi. Project administration: Sung Hee Choi. Resources: Ye Seul Yang, Cheol Min Shin, Man Jin Kim, and Sung Sup Park. Software: Youngji Kim and Sung Hee Choi. Supervision: Sung Hee Choi. Validation: Youngji Kim and Sung Hee Choi. Visualization: Sung Hee Choi. Writing the original draft: Youngji Kim and Sung Hee Choi. Manuscript review and editing: Sung Hee Choi. Gene analysis: Sung Sup Park.

\section{ORCID iDs}

$\begin{array}{ll}\text { Youngji Kim } & \text { https://orcid.org/0000-0001-7463-6915 } \\ \text { Ye Seul Yang } & \text { https://orcid.org/0000-0001-9682-6138 } \\ \text { Sung Sup Park } & \text { https://orcid.org/0000-0003-3754-4848 } \\ \text { Man Jin Kim } & \text { https://orcid.org/0000-0002-9345-6976 } \\ \text { Cheol Min Shin } & \text { https://orcid.org/0000-0003-2265-9845 } \\ \text { Sung Hee Choi } & \text { https://orcid.org/0000-0003-0740-8116 }\end{array}$

\section{REFERENCES}

1. Minchiotti L, Galliano M, Caridi G, Kragh-Hansen U, Peters T Jr. Congenital analbuminaemia: molecular defects and biochemical and clinical aspects. Biochim Biophys Acta 2013;1830:5494-502.

2. Peters T Jr. All about albumin: biochemistry, genetics and medical applications. 1st ed. San Diego (CA): Academic Press, Inc.; 1996.

3. Minchiotti L, Galliano M, Kragh-Hansen U, Peters T Jr. Mutations and polymorphisms of the gene of the major human blood protein, serum albumin. Hum Mutat 2008;29:1007-16.

4. Koot BG, Houwen R, Pot DJ, Nauta J. Congenital analbuminaemia: biochemical and clinical implications. A case report and literature review. Eur J Pediatr 2004;163:664-70.

5. Minchiotti L, Kragh-Hansen U, Campagnoli M, Trapani P. The Albumin Web site [Internet]. AARHUS University and University of Pavia; c2018 [accessed on 2018 May 2]. Available at: http://www. albumin.org.

6. Watkins S, Madison J, Galliano M, Minchiotti L, Putnam FW. A nucleotide insertion and frameshift cause analbuminemia in an Italian family. Proc Natl Acad Sci U S A 1994;91:2275-9.

7. Toye JM, Lemire EG, Baerg KL. Perinatal and childhood morbidity and mortality in congenital analbuminemia. Paediatr Child Health 2012;17:e20-3.

8. Ruffner DE, Dugaiczyk A. Splicing mutation in human hereditary analbuminemia. Proc Natl Acad Sci U S A 1988;85:2125-9.

9. Minchiotti L, Caridi G, Campagnoli M, Lugani F, Galliano M, Kragh-Hansen U. Diagnosis, phenotype, and molecular genetics of congenital analbuminemia. Front Genet 2019;10:336.

10. Yousefzadeh P, Shapses SA, Wang X. Vitamin D binding protein impact on 25-hydroxyvitamin D levels under different physiologic and pathologic conditions. Int J Endocrinol 2014;2014:981581. 